\title{
Brain size differences
}

SIR - Recent claims by Rushton and Ankney of racial and sex differences in brain size $^{1-3}$ are accounted for by a simple artefact of the statistical method employed. I illustrate this effect below.

I focus on the claim that men have larger brains than women, because this difference was the most dramatic of all comparisons made ${ }^{1}$. I use the autopsy measurement of brain weight and body dimensions of Cleveland adults presented by Ho et al. ${ }^{4,5}$. These same data were recently used by Ankney ${ }^{6}$ to bolster the conclusion that men have larger brains than women, once body size differences between men and women are accounted for. This conclusion is currently receiving a great deal of attention in the Canadian press ${ }^{7}$. Ho et al. ${ }^{4,5}$ did not present the raw data, but all necessary quantities can be computed from their tabular summaries. Using linear regression ${ }^{8}$ of brain weight on body size, men and women of the same body size are compared. The men have larger brains on average. For example, mean brain weight of white men $170 \mathrm{~cm}$ tall is about $100 \mathrm{~g}$ greater than of white women of the same height ${ }^{1,6}$. A similar result holds when body weight is used instead ${ }^{6}$.

Do men have larger brains? The flaw in such a claim is forcefully illustrated by a further analysis of these same data. Rather than compare brain sizes between men and women of similar height, I compared mean heights of men and women having the same brain size. If men truly have larger brains for their body size than women, then men should be shorter than women of equal brain weight. Yet the opposite is true: white men are more than $10 \mathrm{~cm}$ taller on average than white women with the same brain weight (see figure). Indeed,

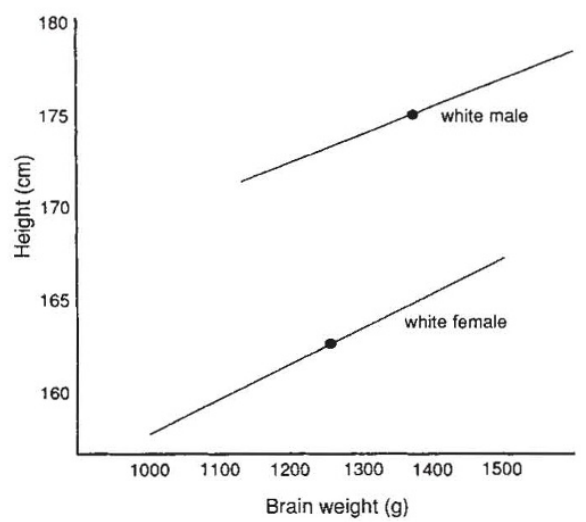

Linear regressions of body height on brain weight in white men and women. Regression statistics were computed from data in $\mathrm{Ho}$ et al. ${ }^{4,5}$ For men, $y=0.015 Y+154.4(n=$ 414). for women, $y=0.19 Y+138.7(n=$ 388). Lines extend two standard deviations to either side of mean brain weight, indicated by the large points. to find a male brain-size category in which mean height is equal to that of women with $1,500 \mathrm{~g}$ brains, it is necessary to extrapolate downward to a male brain of about $850 \mathrm{~g}$. Clearly, by this criterion women have much larger brains than men. The same is true when body weight rather than height is used. Furthermore, racial differences disappear when the data are analysed in the same way.

The source of the conflicting conclusions is the well-known 'regression effect $^{\text {, }}$. This paradox occurs because brain size of individuals varies partly independently of body size, and vice versa. The effect is enhanced in the present case because the causes of size variation between individuals of the same sex (which may be chiefly environmental) are not the same as the causes of differences between the sexes (which may be largely genetic). Hence it makes little sense to use natural variation in brain and body size within sexes to correct for differences between men and women.

\section{Dolph Schluter}

Department of Zoology,

University of British Columbia,

Vancouver, BC, V6T 1 Z4 Canada

SIR - In your comment on Rushton's recent data showing different mean cranial capacities among Asian, Caucasian and Afro-American US Army personnel $^{1}$, you suggest that Caucasian military personnel may be of relatively higher quality, compared to the Caucasian population as a whole, than AfroAmerican, thus producing a biased estimate of the difference in brain size.

This is surely improbable. The US Army administers aptitude tests to potential recruits and accepts only those who score above a minimum threshold. Afro-Americans score lower on aptitude tests than Caucasians, so a greater proportion of Afro-Americans in the lower ability range are screened out by the tests. The admission tests appear to screen out 3.4 per cent of Caucasians and 30 per cent of Afro-Americans ${ }^{9}$. This procedure raises the mean ability levels of both Caucasians and AfroAmericans in the US Army, as compared with the general population, but it raises the mean ability of Afro-American military personnel considerably more than that of Caucasians. The effect is to raise the mean IQ of Caucasians in the US Army by 1 IQ point (100 to 101$)$ and of Afro-Americans by 6 IQ points ( 85 to 91).

The effect of military selection tests in reducing the black-white difference in the general population goes some way towards explaining why the black-white differences for cranial capacity reported by Rushton are much lower than those obtained by Beals, Smith and Dodd ${ }^{10}$. Their study of worldwide data on approximately 20,000 crania found that Caucasians have a mean cranial capacity of $1,362 \mathrm{~cm}^{3}$, indistinguishable from Rushton's figure of $1,361 \mathrm{~cm}^{3}$ for American Caucasian military personnel. But the Beals et al. figure for the cranial capacity of Africans is $1,276 \mathrm{~cm}^{3}$, considerably lower than Rushton's figure of $1,346 \mathrm{~cm}^{3}$ for Afro-Americans in the US Army. The most probable explanation of these differences is that the selection procedures for the US Army exert only minimum bias on the intake of whites but screen out large numbers of low-ability blacks. Thus you are correct in suggesting that there is a bias in Rushton's military sample, but in the opposite direction from that suggested in your comment.

\section{Richard Lynn}

Psychology Department,

University of Ulster,

Coleraine,

Northern Ireland BT52 1SA, UK

SIR - Science does not exist in a vacuum and is therefore subject to all the political, social or economic influences that exist in this world. Political correctness has its place, whether scientists like it or not. Everything relating to science, that is, the method, the data, the interpretations and results, are all as subjective as any other human endeavour (simply because it is a human endeavour). Thus, science and researchers are not immune to attacks from a nonscientific viewpoint such as the politically correct.

The conclusions drawn by Rushton ${ }^{2}$ and Ankney $^{3}$ in the brain size/IQ debate are dubious at best. Mary Warnock, commenting on John Stuart Mill's essay "The Subjection of Women", writes of Mills: "He was not prepared to accept any argument purporting to show that women were naturally inferior in intellect or originality to men. For, he said, there had never been a chance to test such a hypothesis. Only after generations of equal education could any proposition about the powers of women compared with those of men be considered."11 In other words, neither Rushton nor Ankney considered the political, social and economic differences between the sexes. If men and women were educated in an environment where both sexes were equally encouraged to achieve, given equal opportunity, given equal rights and there existed no discrimination of any kind, both sexes would no doubt excel equally in all attributes to mental abilities. If the brain size data are true, this means that women's brains 